\title{
Thermal degradation of organic pollutants in sewage sludge
}

\author{
R. Font, M. F. Gomez-Rico \& A. Fullana \\ Department of Chemical Engineering, University of Alicante, Spain
}

\begin{abstract}
Sewage sludge from a domestic water treatment plant was heated in an air atmosphere at different temperatures $\left(105-500{ }^{\circ} \mathrm{C}\right)$ for 1 hour in order to study the degradation of some organic pollutants. The compounds studied were: linear alkylbenzene sulphonates (LAS) with an alkylic chain of 10-13 atoms of carbon, and nonylphenolic compounds, including nonylphenol (NP) and nonylphenol ethoxylates with 1 and 2 ethoxy groups (NP1EO+NP2EO). These compounds were studied because they frequently exceed the limits proposed for sludge application to land in Europe. The lowest temperature did not show variations with respect to the initial sludge, but at $250^{\circ} \mathrm{C}$ the concentrations of LAS and NP were reduced by around $30 \%$ and NP1EO+NP2EO disappeared. Logically, at $500{ }^{\circ} \mathrm{C}$ all compounds studied were totally removed. The study was completed with a thermogravimetric analysis of LAS, NP and NP1EO+NP2EO separately carried out at different times of treatment and different temperatures. The results showed that an increase of the treatment time at moderate temperatures $\left(<250{ }^{\circ} \mathrm{C}\right)$ reduced the concentrations of NP and NP1EO+NP2EO, which can be interesting since probably the beneficial properties of the sludge for the soil are practically not changed.
\end{abstract}

Keywords: linear alkylbenzene sulphonates, nonylphenolic compounds, thermal degradation, sewage sludge.

\section{Introduction}

Land application is one of the alternatives for the use of the great quantities of sewage sludge generated by WWTPs. When the sludge is applied to soils, their physical properties are improved and they receive nutrients such as nitrogen and phosphorous. However, this may cause the accumulation of potentially 
hazardous components in the soil that were present in the sludge, such as heavy metals and some organic compounds $[1,2]$. The current European regulation in this respect, EU Council Directive 86/278/EEC [3] on the use of sewage sludge in agricultural soils, does not consider the control of organic compounds although a future revision of the Directive will contemplate limit values for them. Several proposals have been presented about these limits [4-7], the most concrete being the third draft of a "Working Document on Sludge" [4], although the final version has not been issued yet. Among the limited compounds, linear alkylbenzene sulphonates with an alkylic chain of 10-13 atoms of carbon (LAS $\mathrm{C}-10$ to $\mathrm{C}-13$ ) and the nonylphenolic compounds, including nonylphenol (NP) and nonylphenol ethoxylates with one or two ethoxy groups (NP1EO+NP2EO), are frequently found in sludges and often exceed the limit concentrations proposed for their use in soils $[2,8]$.

NP, NP1EO and NP2EO are formed in a WWTP as degradation products from non-ionic surfactants, such as those found in specialised cleaning agents, whereas LAS are anionic surfactants widely used in cleaners and detergents for domestic and industrial applications.

Good biodegradations of LAS and NP+NP1EO+NP2EO have been reported in soils with sludge amendments [9], but a decrease of their levels in the sludge before the land application would be more adequate to guarantee that no risk exists with respect to these compounds for the environment.

Drying is usually needed for the sludge after leaving the WWTP for its later use, as it reduces the sludge volume and this involves lower costs of transport and dumping. Moreover, the mechanical dehydration at the WWTP sometimes leaves the sludge with too much water for its best accepted applications: soil amendment (water makes the mixture sludge-soil difficult and heterogeneous, and local contamination can exist) and energy valorisation (the water content reduces the calorific value of the sludge).

Thermal drying of the sludge could be interesting to degrade LAS and $\mathrm{NP}+\mathrm{NP} 1 \mathrm{EO}+\mathrm{NP} 2 \mathrm{EO}$ if the process was carried out at a certain temperature, and therefore ensure the minimum environmental impact with the sludge application. Nevertheless, no studies have been found in the literature in this respect and this is a field that needs further research.

The aim of this work was to carry out a thermal treatment of the sludge at different temperatures to determine the temperature at which LAS and nonylphenolic compounds disappeared in order to consider this option before the use of the sludge if this temperature is not too high to involve a great energy cost.

\section{Experimental}

\subsection{Sewage sludge}

The sewage sludge used was produced in 2005 by a domestic water treatment plant located in Aspe, a rural area of the Region of Valencia (SE Spain), with a water flow of $2167 \mathrm{~m}^{3} \mathrm{~d}^{-1}$ that includes an amount from industry. The main types 
of industry in the area are rubber, shoe and construction materials industries. The sludge was treated by aerobic digestion and filter band dehydration, and this was collected from different points of the filter band.

\subsection{Experimental layout for thermal treatment}

\subsubsection{Treatment by muffle furnace}

A muffle furnace Heron $12 \mathrm{PR} / 300$ was considered for the study of thermal degradation of compounds in sludge, which permits the treatment of a great quantity of material, necessary for the analysis of the compounds in the resultant solid residue.

The thermal treatment was carried out in an air atmosphere at different temperatures: 105,250 and $500{ }^{\circ} \mathrm{C}$. For the study of NP, NP1EO and NP2EO an intermediate temperature was also used, $150{ }^{\circ} \mathrm{C}$, to obtain more information about the changes of these compounds at low temperature. For the LAS this was not necessary since they did not undergo significant changes until a higher temperature.

First of all, the samples were dried in a conventional oven at $105^{\circ} \mathrm{C}$ for $24 \mathrm{~h}$, since such a low temperature is difficult to control in the muffle furnace. Therefore, the sample belonging to the lowest temperature was prepared for the analysis. This previous treatment at $105^{\circ} \mathrm{C}$ was important to remove the water content before increasing the temperature, and therefore to avoid an effect of this water on the samples to reach the corresponding temperature.

With respect to the treatments at $150-500^{\circ} \mathrm{C}$, around $10 \mathrm{~g}$ of sample was kept in the muffle furnace for $1 \mathrm{~h}$ at the respective temperature.

The sampling for the analysis of the interesting compounds was done by collecting the solid residue remaining in the furnace after the treatment.

\subsubsection{Treatment by thermobalance}

Because of the availability of LAS, NP, NP1EO and NP2EO (almost pure standards), a thermogravimetric analysis of them was carried out to observe the temperature at which the main weight loss of each one took place, supposedly corresponding to the temperature at which the compounds disappeared by vaporisation or decomposition, a fact that can help to achieve the objective of this work: the knowledge of the adequate temperature for a thermal treatment of sludge to eliminate certain organic pollutants which are present in the sludge at high levels.

The treatment by muffle furnace was useful to consider the effect of the matrix where the studied compounds were placed, since the sludge can adsorb part of these compounds and modify the decomposition rate. The thermogravimetric treatment, however, was used to complete the study with a high number of simple experiments, considering the combination of temperature and time.

A thermobalance TG-DTA simultaneous Metler Toledo model TGA/SDTA851e/LF/1600 was used. The study with the pure or almost pure compounds was carried out in an air atmosphere and with two different ways of heating: a constant heating rate in the first experiment (dynamic experiment), and 
by keeping a certain temperature for some time in the last experiments, once the temperature of the main weight loss was known by the first experiment.

The compounds used for the thermobalance were: 4-nonylphenol (technical, Dr. Ehrenstorfer), 4-Nonylphenol-ethoxylate (technical, including NP1EO+NP2EO 1:1, Dr. Ehrenstorfer) and Na-LAS P-550 (Petresa, San Roque, Spain), with an average alkyl chain of 11.6 and an homologue distribution of $12.1 \%, 34.1 \%, 30.6 \%$ and $23.2 \%$ respectively for LAS with an alkylic chain of 10 to 13 carbon atoms. The content of impurities in this mixture was below $1 \%$.

The experimental conditions were the following:

For LAS, the first experiment was carried out with a constant heating rate of $10^{\circ} \mathrm{C} \mathrm{min}{ }^{-1}$. The second experiment was done with a heating rate of $10^{\circ} \mathrm{C} \mathrm{min}^{-1}$ until $300{ }^{\circ} \mathrm{C}$, maintaining this temperature for $1 \mathrm{~h}$ and finally heating at $10^{\circ} \mathrm{C}$ $\mathrm{min}^{-1}$. The following experiments were done with a heating rate of $10^{\circ} \mathrm{C} \mathrm{min}{ }^{-1}$ until 150,200 or $300{ }^{\circ} \mathrm{C}$, keeping this temperature for $5 \mathrm{~h}$ and finally heating at $10^{\circ} \mathrm{C} \mathrm{min}{ }^{-1}$. The final temperature was $1000^{\circ} \mathrm{C}$.

For nonylphenolic compounds, the first experiment had a constant heating rate of $10{ }^{\circ} \mathrm{C} \mathrm{min}{ }^{-1}$. The second experiment consisted of a heating rate of $10{ }^{\circ} \mathrm{C}$ $\min ^{-1}$ until $150{ }^{\circ} \mathrm{C}$, maintaining this temperature for $1 \mathrm{~h}$ and finally heating at 10 ${ }^{\circ} \mathrm{C} \mathrm{min}{ }^{-1}$. The following experiments were done with a heating rate of $10^{\circ} \mathrm{C} \mathrm{min}$ ${ }^{1}$ until 70 or $100^{\circ} \mathrm{C}$, maintaining this temperature for $5 \mathrm{~h}$ and finally heating at $10{ }^{\circ} \mathrm{C} \mathrm{min}^{-1}$.

The mass of compounds used for the experiments was $5 \mathrm{mg}$, and the atmosphere was $\mathrm{He}: \mathrm{O}_{2}(4: 1$, similar to the oxygen proportion in air) for combustion.

\subsection{Analysis of organic compounds}

\subsubsection{LAS}

For the analysis of LAS in the solid residue remaining after the muffle treatment, the method described by Prats et al. [10] was used. Samples were stabilized with a formaldehyde solution, dried and around $10 \mathrm{~g}$ were extracted with methanol using the Soxhlet method [11]. The resultant extract was purified with a quaternary amine column, where LAS were eluted with $4 \mathrm{~N}$ hydrochloric acid in methanol, and a C-18 column, where LAS were eluted with methanol. The analysis of the extract was carried out by high performance liquid chromatography (HPLC) and ultraviolet detection. The HPLC used was Agilent 1100 Series with the detector at $225 \mathrm{~nm}$ and a chromatographic column LiChrosorb RP-18, $5 \mu \mathrm{m}$ particle size diameter. The mobile phase was methanol/water $80 / 200.5 \mathrm{M}$ in $\mathrm{NaClO}_{4}$, with a flow rate of $1 \mathrm{~mL} \mathrm{~min}{ }^{-1}$. The equipment was calibrated with several solutions of the standard Na-LAS P-550, previously used for the treatment by thermobalance

\subsubsection{NP+NP1EO+NP2EO}

An internal standard (4-n-Nonylphenol ring ${ }^{13} \mathrm{C}_{6}$; Cambridge Isotope Laboratories) was poured into around $10 \mathrm{~g}$ of sample and then this was dried by adding anhydrous sodium sulphate and extracted with hexane:acetone (1:1) by the Soxhlet method [11]. The solvent of the extracts was then changed to 
dichloromethane, and the extracts were cleaned by using size exclusion chromatography [12] (Jordi GPC column, $680 \mathrm{~mm}$ x $22 \mathrm{~mm}$ I.D.). The column was eluted with dichloromethane at a flow rate of $5 \mathrm{~mL} \mathrm{~min}{ }^{-1}$, and a fraction was collected at 25-55 minutes for its analysis by gas chromatography/mass spectrometry (GC/MS) with a Fisons GC8000 gas chromatograph and a MS800 mass spectrometer following the recommendations from the US EPA [13]. A DB-5 GC column (60 m x $0.25 \mathrm{~mm}$ ID) was used for the chromatograph and a positive electronic impact $(\mathrm{EI}+)$ source was employed for the mass spectrometer. The SIR (selected ion recording) mode was used to detect exclusively the characteristic ions of the compounds of interest.

The external standards used were 4-Nonylphenol (technical, Dr. Ehrenstorfer) and 4-Nonylphenol-ethoxylate (technical, Dr. Ehrenstorfer), previously used for the treatment by thermobalance. The internal standard (surrogate) was 4-nNonylphenol ring ${ }^{13} \mathrm{C}_{6}$.

\section{Results}

\subsection{Decomposition observed after the treatment in muffle furnace}

\subsubsection{Levels with respect to the residue mass}

Fig. 1 shows the results of the treatments at $105-500{ }^{\circ} \mathrm{C}$. The resultant total levels and the concentrations of the individual compounds are shown in these figures, as well as the levels of the initial sludge without treatment. It is important to clarify that these concentrations were calculated with respect to the mass of residue after the treatment. They do not refer to the initial mass of sludge (except logically for the sludge without treatment.), since the solid resultant from the treatment is the material to be used for the appropriate purposes.

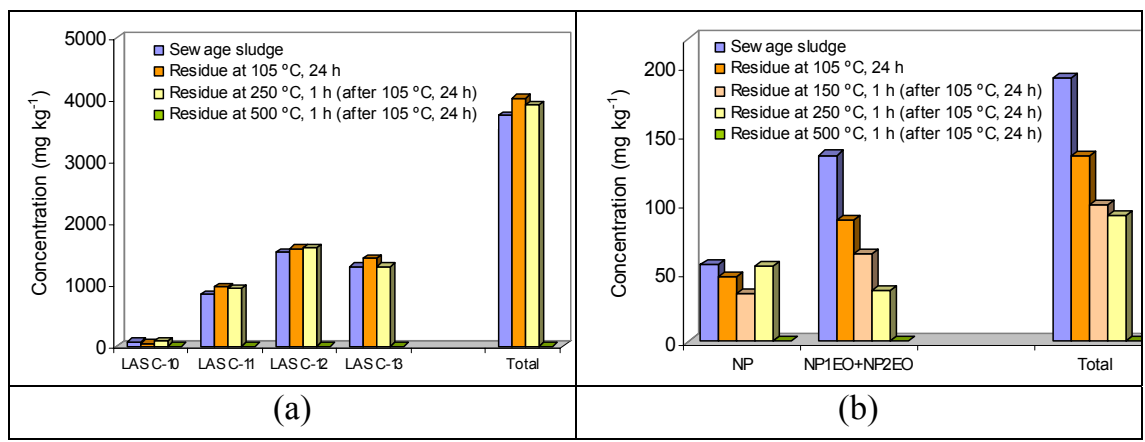

Figure 1: $\quad$ LAS (a) and NP+NP1EO+NP2EO (b) levels in the residue after treatment by muffle furnace in dry weight (d.w.).

With respect to LAS (fig. 1.a), a significant decrease was observed at $500{ }^{\circ} \mathrm{C}$, but no important change was detected at low temperatures $\left(105-250{ }^{\circ} \mathrm{C}\right)$. With respect to NP, NP1EO and NP2EO (Fig. 1.b), NP did not significantly decrease its concentration until the highest temperature, but the nonylphenol ethoxylates 
followed a downward trend from low temperatures, achieving a reduction of $50 \%$ at $150{ }^{\circ} \mathrm{C}$ and $70 \%$ at $250{ }^{\circ} \mathrm{C}$. At this point, the levels were still much higher than the proposed limit of $50 \mathrm{mg}$ total $\mathrm{NP}+\mathrm{NP} 1 \mathrm{EO}+\mathrm{NP} 2 \mathrm{EO} \mathrm{\textrm {kg } ^ { - 1 }}$ [4], an important fact if the destination of the material is application to land, although the reduction achieved was good. A total disappearance of LAS and $\mathrm{NP} 1 \mathrm{EO}+\mathrm{NP} 2 \mathrm{EO}$ was observed at $500{ }^{\circ} \mathrm{C}$ but at this temperature the sludge had totally decomposed.

\subsubsection{Levels with respect to the initial sludge mass}

Since the concentrations shown in fig. 1 refer to the resultant residue but not to the initial sludge, the values are affected by the decomposition of part of the sludge due to the thermal treatment, which is related to a concentration of the material (table 1). Nevertheless, if the levels of compounds refer to the initial mass of sludge, these levels are lower and the real elimination of compounds can be observed, without including the effect of other parameters.

Table 1: $\quad$ Solid concentration during the thermal treatment.

\begin{tabular}{|l|c|c|c|c|c|}
\hline & $\begin{array}{c}\text { Inicial } \\
\text { sludge }\end{array}$ & $\begin{array}{c}\text { Residue } \\
105^{\circ} \mathrm{C}\end{array}$ & $\begin{array}{c}\text { Residue } \\
150^{\circ} \mathrm{C}\end{array}$ & $\begin{array}{c}\text { Residue } \\
250{ }^{\circ} \mathrm{C}\end{array}$ & $\begin{array}{c}\text { Residue } \\
500^{\circ} \mathrm{C}\end{array}$ \\
\hline $\begin{array}{l}\text { Concentration } \\
\text { (kg initial sludge } / \mathrm{kg} \\
\text { residue) }\end{array}$ & 1.00 & 1.00 & 1.05 & 1.51 & 4.98 \\
\hline
\end{tabular}

This solid concentration was calculated through the weight of residue after treatment with respect to the weight of the initial sludge (dry weight), and assuming that the initial concentration of the sludge was $100 \%$. It can be observed that the concentration factor at 250 and $500{ }^{\circ} \mathrm{C}$ was high. Fig. 2 shows the levels of compounds with respect to the initial sludge, after removing the effect of the material concentration.

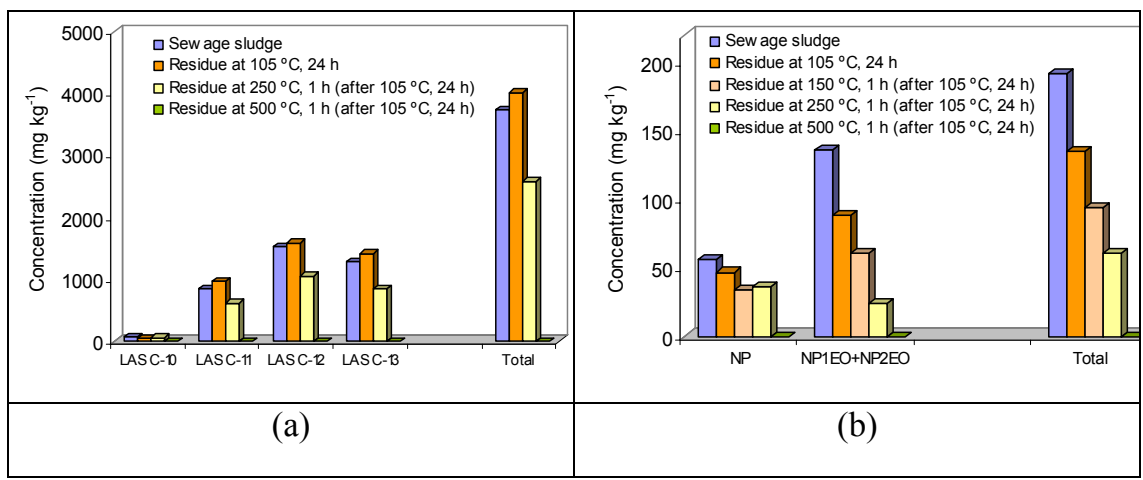

Figure 2: $\quad$ LAS (a) and NP+NP1EO+NP2EO (b) levels after treatment by muffle furnace with respect to the initial sludge in dry weight (d.w.). 
With respect to LAS (fig. 2.a), it can be pointed out that these compounds started to decrease at temperatures of $105-250{ }^{\circ} \mathrm{C}$. At $250{ }^{\circ} \mathrm{C}$ the levels found were $65-70 \%$ of the initial values; this decrease affected the four compounds in the same way. In the literature, it has been observed that LAS can be eliminated at temperatures around $250{ }^{\circ} \mathrm{C}$ and a prolonged time [14], which agrees with the results of this work, although in this study the time has not been too long.

With respect to nonylphenolic compounds (fig 2.b), the decrease started the same temperature range as LAS, $105-250{ }^{\circ} \mathrm{C}$. However, this decrease was not produced for the three compounds in the same way, since at $250{ }^{\circ} \mathrm{C} \mathrm{NP1EO}$ and NP2EO disappeared completely but not NP. NP is a degradation product from NP1EO and NP2EO, and therefore its decrease must be more difficult. At 250 ${ }^{\circ} \mathrm{C}$, NP levels of $60 \%$ of the initial concentration in the sludge were found, but with respect to NP1EO+NP2EO the values were $17 \%$.

\subsection{Decomposition observed by thermogravimetric analysis}

\subsubsection{Dynamic runs}

Curves of weight loss of compounds as a mass fraction with respect to the initial mass versus temperature were obtained for the total LAS C-10 to C-13, NP and NP1EO+NP2EO standards. The thermograms (TG) resulting from the dynamic experiment are shown in fig. 3 .

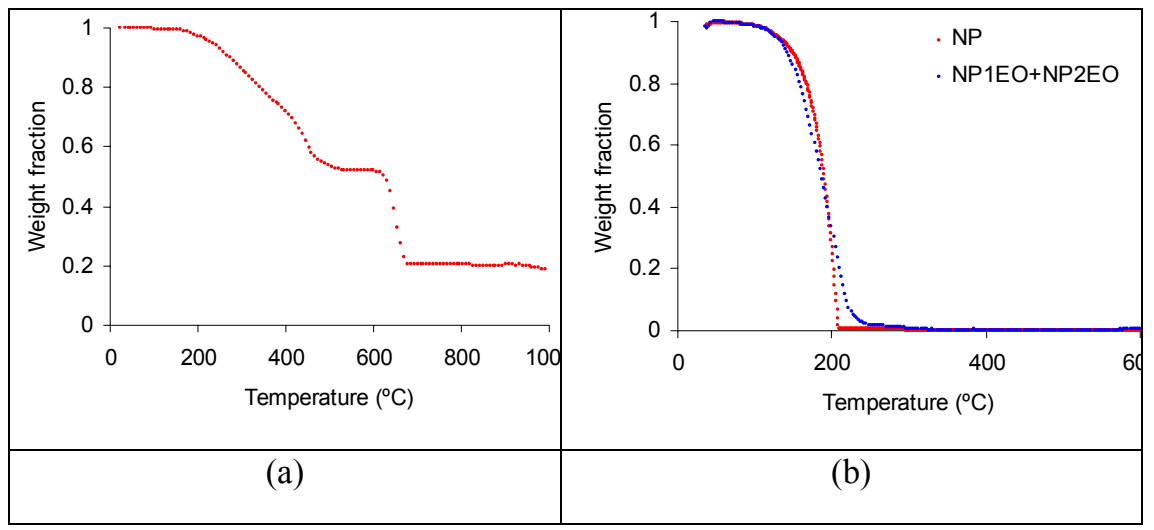

Figure 3: $\quad$ LAS (a) and NP with NP1EO+NP2EO (b) TG obtained from the dynamic experiment in combustion.

For the LAS mixture (fig. 3.a), a first weight loss can be observed at 200-400 ${ }^{\circ} \mathrm{C}$, a slight change of shape at $400-500{ }^{\circ} \mathrm{C}$ and an abrupt decrease at $600-700{ }^{\circ} \mathrm{C}$. Nevertheless, the curve does not end at zero weight since LAS are compounds with sodium and this is part of the final residue. The curve corresponds to a mixture of four different compounds (C-10 to C-13), but all of them are lost with the same pattern as seen is the muffle experiments, and the main LAS loss occurs at $200-500{ }^{\circ} \mathrm{C}$ (fig. 2) by decomposition to give intermediate lighter compounds. This agrees with the degradation temperature found in the literature for these 
compounds [15], $444{ }^{\circ} \mathrm{C}$. The last abrupt loss corresponds to the intermediate products degradation, which could be the break up of the aromatic ring.

With respect to the nonylphenolic compounds (fig. 3.b), NP presents an abrupt weight loss at $125-215{ }^{\circ} \mathrm{C}$, ending at zero weight. NP1EO+NP2EO, however, present a weight loss that starts at $125{ }^{\circ} \mathrm{C}$ but ends at $300{ }^{\circ} \mathrm{C}$ at zero weight with a lower slope. This could be due to the decomposition of NP1EO+NP2EO to give NP before disappearing completely. The shape of the NP curve is similar to the typical TGs of volatilisation, with a vertically decrease from high weight to zero weight and a sharp ending [16]. Therefore, it is possible that NP was volatilised instead of decomposed. The boiling point for NP is not too high, 293-297 ${ }^{\circ} \mathrm{C}$, although these temperatures are higher than the temperatures of the main weight loss obtained in this study, and decomposition could have some influence as suggested in the literature [17]. Nevertheless, volatilisation seems to be the main cause, since lower temperatures and higher times achieved a decrease of the NP levels, as presented in the following section. Considering NP1EP+NP2EO, their boiling points could not be obtained since they decompose before boiling, and therefore the decomposition to give NP was the main cause of elimination.

\subsubsection{Experiments of keeping a low temperature for some time}

Abu-Hassan et al. [14] observed a LAS removal at temperatures of $250{ }^{\circ} \mathrm{C}$ and at elevated times, although with different treatment than this work. Therefore, it was decided to carry out new thermogravimetric analyses at relatively low temperatures and high times. The results are shown in fig. 4.

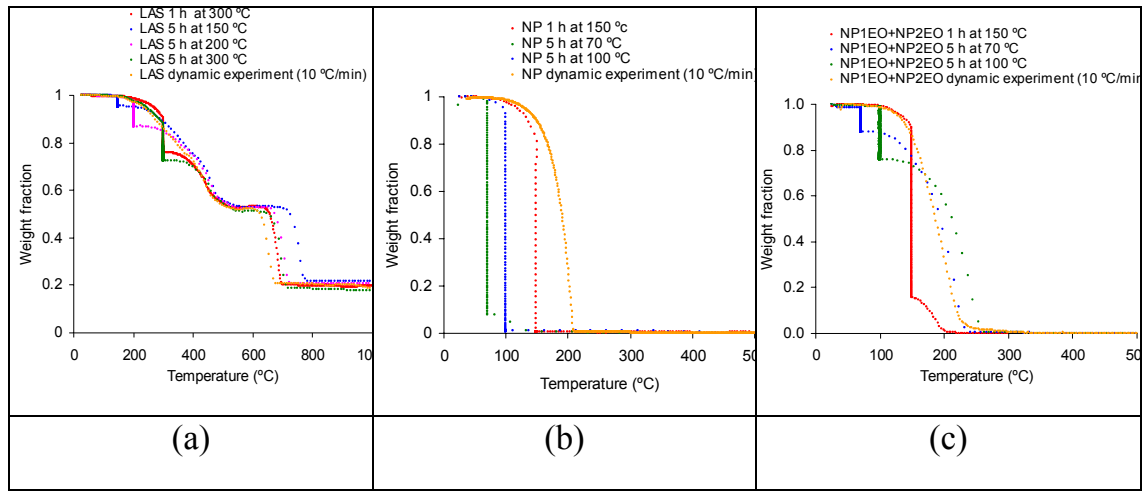

Figure 4: $\quad$ LAS (a), NP (b) and NP1EO+NP2EO (b) TG obtained from the experiments at a certain temperature and high times in combustion, and comparison with the dynamic experiment.

With respect to LAS (fig. 4.a), the variations were small, even considering the dynamic experiment, and therefore a high time does not improve the elimination of LAS. With respect to NP (fig. 4.b), it can be observed that a temperature of 70 ${ }^{\circ} \mathrm{C}$ for $5 \mathrm{~h}$ produced a great elimination of this compound, although this possibly means long and expensive treatment. The best option was the treatment at $150{ }^{\circ} \mathrm{C}$ 
for $1 \mathrm{~h}$, where time was reduced and the removal of NP was complete. Considering NP1EO+NP2EO (fig. 4.c), this option was also the best, since with lower temperatures and longer times the disappearance was not significant. This could be seen by representing weight fraction versus time.

\subsection{Comparison of the results for the two types of runs: TG and muffle furnace}

With respect to LAS, a decrease in the concentration was observed at $250{ }^{\circ} \mathrm{C}$ by muffle treatment, but by TG there was no significant weight loss, since LAS can decompose at this temperature to produce intermediate compounds, which does not vary the weight significantly. Considering NP+NP1EO+NP2EO, with the combination of both treatments it can be said that a total disappearance of NP1EO and NP2EO was produced at $150-250{ }^{\circ} \mathrm{C}$ by decomposition, although NP needs higher temperatures since this is a product of nonylphenol etoxylates degradation. The differences between the two treatments are probably due to the sorption of these compounds by the sludge. The comparison was done with the results of the muffle treatment with respect to the initial sludge.

\section{Conclusions}

Treatment at a relatively low temperature, $105^{\circ} \mathrm{C}$ for $24 \mathrm{~h}$ and $250{ }^{\circ} \mathrm{C}$ for $1 \mathrm{~h}$, slightly reduces the levels of LAS and NP by around $30 \%$, and decreases the levels of NP1EO+NP2EO by around $87 \%$. An increase in time at a low temperature $\left(150^{\circ} \mathrm{C}\right)$ can reduce the concentration of NP and NP1EO+NP2EO, which could be interesting in some cases.

\section{Acknowledgement}

Support for this work was provided by project CTQ2005-05262 (Ministerio de Educación y Ciencia, Spain).

\section{References}

[1] European Commission Scientific and Technical Sub-component Report, Disposal and recycling routes for sewage sludge. European Commission DG Environment - B/2, 132 pp., 2001.

[2] European Commission, Organic contaminants in sewage sludge for agricultural use. Report of the European Commission Joint Research Centre, Ispra, 73 pp., 2001.

[3] CEC, Council of the European Communities, Council Directive of 12 June 1986 on The protection of the environment, and in particular of the soil, when sewage sludge is used in agriculture (86/278/EEC). Official Journal of the European Communities No. L 181, pp. 6-12, 1986.

[4] EU, Working document on sludge, $3^{\text {rd }}$ draft. Brussels, 19 pp., 2000, http://ec.europa.eu/environment/waste/sludge/pdf/sludge_en.pdf 
[5] EU, Working document on biological treatment on biowaste, $2^{\text {nd }}$ draft. DG ENV.A.2, Brussels, 22 pp., 2001. http://www.compost.it/www/ pubblicazioni_on_line/biod.pdf

[6] EU, Draft discussion document for the ad hoc meeting on biowastes and sludges, Brussels, 22 pp., 2003.

[7] European Commission, Evaluation of the relevance of organic micropollutants in sewage sludge. Provisional report for commenting. Results of a JRC-Coordinated Survey on background values. Gawlik, B.M., Bidoglio, G. (eds.). Office for Official Publications of the European Communities, Luxembourg, 51 pp., 2004.

[8] Gomez-Rico, M.F., Font, R., Aracil, I. \&, Fullana, A., Analysis of organic pollutants in sewage sludges from the Valencian Community (Spain). Archives of Environmental Contamination and Toxicology, 52(3), pp. 306316, 2007.

[9] Gomez-Rico, M.F., Font, R., Vera, J., Fuentes, D., Disante, K. \& Cortina, J., Degradation of organic pollutants in Mediterranean forest soils amended with sewage sludge, Chemosphere, in press, 2008.

[10] Prats, D., Ruiz, F., Vázquez, B. \& Rodríguez-Pastor, M., Removal of anionic and nonionic surfactants in a wastewater treatment plant with anaerobic digestion. A comparative study. Water Research, 31(8), pp. 1925-1930, 1997.

[11] US EPA, Method 3540C: Soxhlet extraction. Test Methods for Evaluating Solid Waste, Physical/Chemical Methods (SW-846), U.S. Environmental Protection Agency's Office of Solid Waste: Washington, 8 pp., 1996.

[12] US EPA, Method 3640A: Gel-permeation cleanup. Test Methods for Evaluating Solid Waste, Physical/Chemical Methods (SW-846), U.S. Environmental Protection Agency's Office of Solid Waste: Washington, 24 pp., 1994.

[13] US EPA, Method 8270C: Semivolatile organic compounds by gas chromatography/mass spectrometry (GC/MS). Test Methods for Evaluating Solid Waste, Physical/Chemical Methods (SW-846), U.S. Environmental Protection Agency's Office of Solid Waste: Washington, 54 pp., 1996.

[14] Abu-Hassan, A.M., Mantzavinos, D. \& Metcalfe, I.S., Wet air oxidation and ultrasound for the removal of linear alkylbenzene sulfonates from wastewater. The beneficial role of catalysis. Topics in Catalysis, 33(1-4), pp. 141-148, 2005.

[15] OECD SIDS (Screening Information Data Sets), Linear alkylbenzene sulfonate (LAS). SIDS Initial Assessment Report for 20 $0^{\text {th }}$ SIAM, Paris, 397 pp., 2005. http://www.chem.unep.ch/irptc/sids/oecdsids/LAS.pdf.

[16] Hazra, A., Dollimore, D. \& Alexander, K., Thermal analysis of the evaporation of compounds used in aromatherapy by thermogravimetry, Termochimica Acta, 392-393, pp. 221-229, 2002.

[17] EU, 4-Nonylphenol (branched) and nonylphenol. European Union Risk Assessment Report. Final Report, Oxford, 383 pp., 2001. http://ecb.jrc.it/DOCUMENTS/Existing-Chemicals/RISK_ASSESSMENT/ DRAFT/R017_0104_env_hh.pdf. 